\title{
Capas de discos de rock brasileiro dos anos 1980: proposta de modelo de análise visual de conjuntos de artefatos gráficos
}

\author{
1980s Brazilian rock album covers: \\ proposal for a visual analysis model of sets of graphic artifacts
}

Paulo Eduardo Moretto, Priscila Lena Farias

modelo de análise visual, linguagem visual, memória gráfica, cultura material, capas de disco

Este artigo propõe a sistematização de um modelo de análise visual para conjuntos de peças gráficas, buscando uma compreensão mais aprofundada desses artefatos, seus conteúdos, e suas técnicas, incluindo a relação entre a linguagem visual que os articula e a cultura visual do período no qual foram produzidos. O referido modelo foi elaborado tendo por base o processo de análise visual de um conjunto de capas de discos de rock brasileiro dos anos 1980. Análises parciais realizadas anteriormente pelos autores são levadas em consideração na discussão e interpretação dos resultados obtidos.

visual analysis model, visual language, graphic memory, material culture, album covers

This article proposes the systematization of a visual analysis model for sets of graphic pieces, seeking a deeper understanding of these artifacts, their contents, and their techniques, including the relationship between the visual language that articulates them and the visual culture of the period in which they were produced. This model was elaborated based on the process of visual analysis of a set of Brazilian rock album covers from the 1980s. Partial analyzes carried out previously by the authors are taken into consideration in the discussion and interpretation of the results obtained.

\section{Introdução}

Este artigo é parte de uma pesquisa mais ampla que tem como objeto de estudo o design das capas $^{1}$ de disco de rock brasileiro dos anos 1980 (em especial as de bandas surgidas em São Paulo, Rio de Janeiro e Brasília, epicentros da cultura jovem e do rock nacional naquela década). Busca-se compreender estes artefatos a partir de análises centradas em aspectos históricos, culturais, estéticos e, principalmente, em sua linguagem visual.

Os objetivos da pesquisa relatada neste artigo foram o levantamento de critérios e a elaboração de um modelo de análise de artefatos gráficos com vistas a identificar características recorrentes que possam configurar sua linguagem visual. Com base nesse

\footnotetext{
${ }^{1}$ No Brasil, a palavra capa é usada tanto para o objeto físico (a embalagem ou o envelope de papel), quanto para a face principal deste objeto. Esta pesquisa é, salvo ressalvas, sobre o design das faces principais.
} Curitiba | Brazil | 2021 
modelo, desenvolvido a partir da análise das capas de disco em estudo, apresentam-se, na segunda parte do artigo, suas aplicações potenciais.

\section{Referências metodológicas}

Para analisar peças gráficas e elaborar um modelo de análise, foram utilizados estudos sobre design gráfico e linguagem visual, que apresentam princípios básicos e organizam um léxico comum para se pensar o design. Entre eles, pode-se mencionar Novos fundamentos do design (Lupton \& Phillips, 2008), no qual são apresentados as estruturas formais do design gráfico, seus princípios visuais, bem como as relações que se estabelecem entre seus elementos visuais constitutivos.

Outro estudo que guiou as análises feitas ao longo desta pesquisa foi o de Isabella Aragão (2011) sobre os rótulos de cachaça de Pernambuco, no qual são propostos os conceitos de plural e singular, e que toma como referência os princípios da linguagem gráfica descritos pelo teórico britânico Michael Twyman (1986) - elementos pictóricos, verbais e esquemáticos. Elementos visuais plurais, segundo a autora, são recorrentemente usados na criação de peças gráficas de um dado lugar em uma determinada época; por outro lado, elementos singulares são únicos e individualizam algumas dessas peças. Os elementos plurais caracterizam padrões e os singulares as particularidades, e ambos ajudam a compreender a articulação da linguagem visual de um conjunto de artefatos gráficos.

Para analisar os contextos nos quais as peças gráficas selecionadas se inserem, dois outros estudos, pautados na teoria da semiótica e que consideram as dimensões sintática, semântica e pragmática na análise visual de artefatos gráficos, mostraram-se pertinentes. Em Comprehensibility of illustration - an analytical model (Goldsmith, 1980), a autora apresenta um modelo de análise de ilustrações que cruza as dimensões sintática, semântica e pragmática com quatro fatores visuais (unidade, espacialidade, ênfase e paralelismo com textos), resultando em doze aspectos (ou instâncias) a serem considerados na análise de uma ilustração.

Já em Semiótica e tipografia: apontamentos para um modelo de análise (Farias, 2016), o modelo de análise tipográfica é elaborado, analogamente ao modelo descrito anteriormente, com base no cruzamento das mesmas três dimensões com cinco níveis de leitura (letra, palavra, texto, página e volume). Para cada uma das quinze intersecções possíveis, foram geradas listas de tópicos a serem observados ao se aplicar o modelo proposto.

Recorreu-se também à tese de doutorado sobre a tipografia pós-moderna em trabalhos selecionados para as Bienais de Design Gráfico da ADG, a Associação de Designers Gráficos (Migliari, 2010), que elencou uma série de características apresentadas em textos de autores como Steven Heller, Frederic Jameson e Linda Hutcheon. Entre essas características, destacam-se: tipografia eclética, justaposição de pesos e espacejamentos extremos, tipografia deteriorada, distorção, legibilidade difusa e referências vernaculares, várias dessas observadas no caso específico das capas de disco do rock brasileiro dos anos 1980. 


\section{Corpus e primeiras análises}

As capas de discos que constituem o corpus da pesquisa da qual este estudo faz parte foram encontradas em lojas especializadas ou feiras de discos de vinil da cidade de São Paulo e serviram de base para as análises preliminares e a elaboração do modelo apresentado neste artigo. Alguns procedimentos de análise permitiram um entendimento mais apurado da linguagem visual das capas em estudo. Essa sequência de procedimentos configurou um modelo de análise visual para este conjunto de peças gráficas que pode, mediante ajustes, servir para analisar outros conjuntos de artefatos gráficos.

O primeiro procedimento adotado foi o levantamento, na internet, de imagens das capas dos discos lançados no período estudado. A organização de um acervo digital preliminar permitiu tabular os primeiros dados sobre as capas, como títulos dos álbuns, bandas e anos de lançamento. Em paralelo, iniciou-se a busca em lojas especializadas para a formação de um acervo físico. O corpus da pesquisa foi delimitado em um conjunto representativo de 90 discos, produzidos entre 1979 e 1993, por 41 bandas, muitas delas do chamado "mainstream", e normalmente associadas ao subgênero musical BRock ou Brazilian Rock.

Os dois acervos (digital e físico) foram complementares. O primeiro agilizou o início da pesquisa, permitindo identificar caminhos a seguir. O segundo, compilado com maior investimento de recursos financeiros e tempo, possibilitou, com o acesso constante aos artefatos gráficos, a observação mais acurada e análises mais detalhadas.

Dados referentes aos aspectos morfológicos e aos elementos visuais constituintes das peças gráficas foram coletados, tabulados e analisados (Moretto \& Farias, 2021). Na Tabela 1 , podemos observar um detalhe da planilha, na qual cada linha corresponde a uma capa de disco, e as colunas apresentam valores ou siglas que descrevem a Estrutura (E), que pode ser Plural $(P)$, Plural com pequenas alterações $(P+)$ ou Singular $(S)$; o Número de elementos verbais na capa ( $N$, valor numérico); o Tratamento dado aos diversos elementos verbais $(T)$, que pode ser Igual (I) ou Diferente (D); e o Elemento Verbal Principal (EV). Neste último conjunto de colunas, observa-se se o elemento verbal principal é o Nome da Banda ou o Título do álbum $(\mathrm{N} / \mathrm{T})$, se seu tratamento é homogêneo ou heterogêneo $(\mathrm{Ho} / \mathrm{He})$ e, por fim, indica-se, na coluna Caixa (C), se as letras estão em Caixa Alta (CA), Caixa Baixa (cb), Caixa Alta e Baixa (CAb) ou Versalete ( $\mathrm{Vv}$ ). Nas colunas Caracteres Tipográficos (CT) e Letras Manuscritas ou Desenhadas (LMD), utilizam-se as seguintes siglas para descrever os estilos de letra:

Serifadas (S), Sem Serifa (SS), Geométrica (G), Cursiva (C), Tridimensional (T) ou Variada (V).

Os dados coletados na planilha permitiram uma análise preliminar, de cunho predominantemente morfológico sintático. Esta análise considerou os princípios de composição (Lupton \& Phillips, 2008) e de linguagem visual (Twyman, 1986), analisados segundo os conceitos de "plural" e "singular" (Aragão, 2011), e de características do pós-modernismo (Migliari, 2010). Foi possível identificar uma estrutura visual recorrente constituída por um elemento pictórico dominante na composição (fotografia ou ilustração) e dois elementos verbais (nome da banda e título do álbum). Outra característica comum observada se refere ao nome da banda, que costuma ser o principal elemento verbal, normalmente em caixa alta, e 
localizado no topo da capa, enquanto o título do álbum (também frequentemente grafado em caixa alta, mas em corpos menores e em letras com diferentes desenhos) é menos evidente e comumente situado na parte inferior da capa.

Figura 1: Detalhe de planilha com tabulação do levantamento dos elementos pictóricos e verbais principais das capas de disco em estudo.

\begin{tabular}{|c|c|c|c|c|c|c|c|c|c|c|c|}
\hline \multirow{2}{*}{ ano } & \multirow{2}{*}{ banda } & \multirow{2}{*}{ album } & \multirow{2}{*}{ E } & \multirow{2}{*}{$\mathrm{N}$} & \multirow{2}{*}{$\mathbf{T}$} & \multicolumn{5}{|c|}{ EV (elemento verbal principal) } & \multirow{2}{*}{ pós-modernismo } \\
\hline & & & & & & $N / T$ & $\mathrm{Ho} / \mathrm{He}$ & C & CT & LMD & \\
\hline 1983 & Blitz & Radioatividade & $\mathrm{s}$ & 2 & D & $\mathrm{N}$ & Ho & CA & - & SS & $\begin{array}{l}\text { distorção (tipo), } \\
\text { colagem (layout) }\end{array}$ \\
\hline 1983 & Os Paralamas do Sucesso & Cinema mudo & $\mathrm{P}+$ & 2 & 1 & $\mathrm{~N}$ & Ho & CA & sS & - & elementos ornamentais (layout). \\
\hline 1984 & Os Paralamas do Sucesso & Opasso do liti & s & 2 & 1 & $\mathrm{~N}$ & Ho & CA & sS & - & desconstrução (layout) \\
\hline 1984 & Ritchie & ... e a vida continua & $\mathrm{P}$ & 2 & D & $\mathrm{N}$ & Ho & CA & - & c & $\begin{array}{l}\text { desconstruçāo (tipo), } \\
\text { uso dos ornamentos (layout), } \\
\text { elementos tecnológicos }\end{array}$ \\
\hline 1985 & Carnisa de Vênus & Bataltröes de estranitos & $\mathrm{P}$ & 2 & D & $\mathrm{N}$ & Ho & $\mathrm{Cab}$ & SS & - & $\begin{array}{l}\text { fonte caligráfica (lipo), } \\
\text { intervenções com grafismos } \\
\text { (layout) }\end{array}$ \\
\hline 1985 & Kid Abelha e os Abóboras Selvagens & Educação sentimental & $\mathrm{P}$ & 2 & D & $\mathrm{N}$ & $\mathrm{He}$ & CA & SS & - & profusão de fontes \\
\hline
\end{tabular}

$\mathrm{Na}$ análise do material selecionado, notou-se que muitas das capas incluíam imagens dos músicos como principal elemento pictórico, normalmente retratando-os em poses semelhantes. Observou-se também, entre outras características, o uso frequente de colagens ou a reapropriação de imagens e a criação de ilustrações com estilos de outros contextos históricos (e estéticos) como principal elemento pictórico das capas estudadas (figura 2).

Figura 2 - Capas de álbuns com diferentes tipos de elementos pictóricos: Cinema mudo/ Paralamas do Sucesso (Ricardo Leite, 1983/Brasil), Fausto Fawcett e os robôs efêmeros/Fausto Fawcett (Jorge Barrão e Luiz Zerbini, 1987/Brasil) e Cabeça Dinossauro/Titãs (Sérgio Britto, 1986/Brasil).
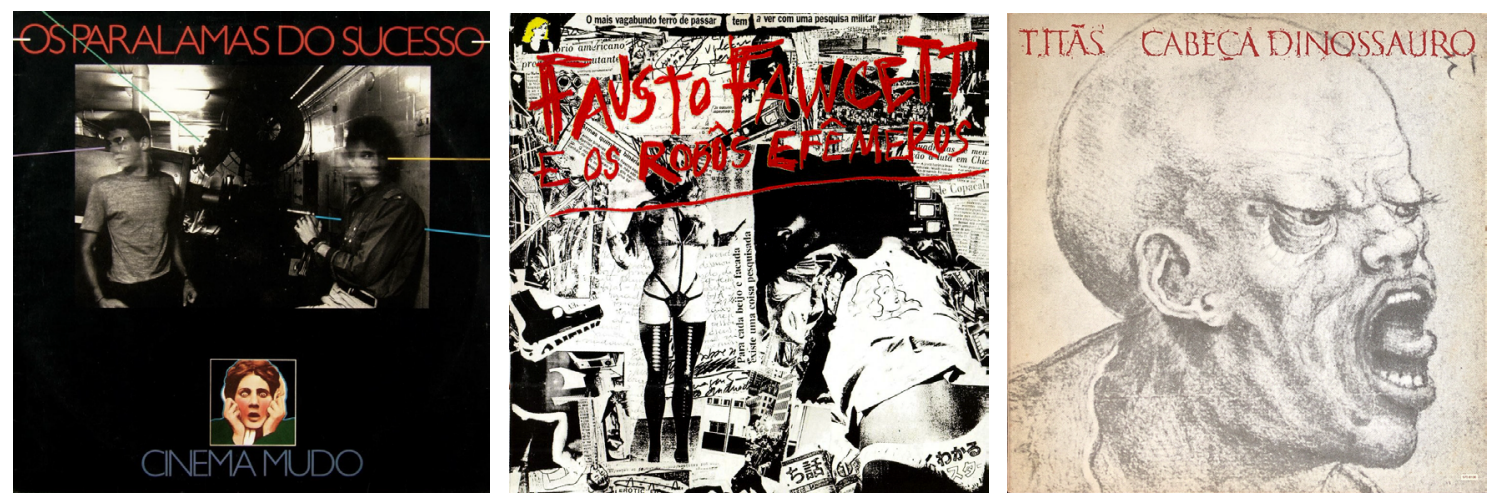

Esses grupos de capas com características comuns passaram, então, a ser analisados em maior profundidade, buscando-se identificar subgrupos com aspectos peculiares em comum. No caso das capas com fotos de bandas, por exemplo, foram identificados três subgrupos: capas com retratos das bandas em fundo neutro, capas com retratos das bandas em um cenário e capas com retratos das bandas com intervenções gráficas. Uma síntese dos aspectos analisados pode ser observada no quadro sinótico (tabela 1). 
Tabela 1: Aspectos analisados nas capas de discos em estudo.

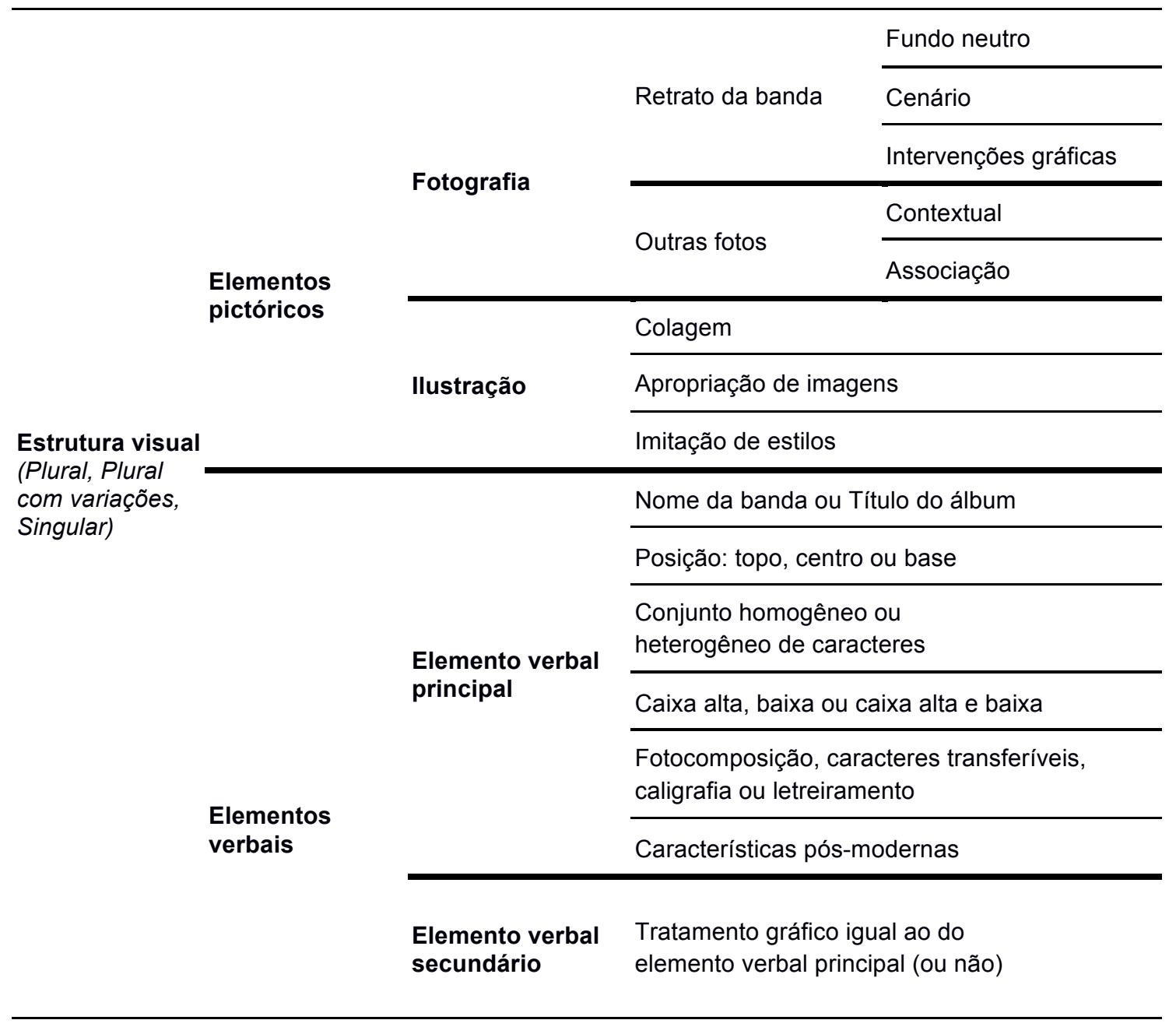

A partir desse ponto, além das características morfológicas das capas, foi analisada também a maneira como tais características relacionam-se com seus potenciais comunicacionais, assim como com suas referências visuais e culturais, incorporando à análise aspectos relativos às dimensões semântica e pragmática desses artefatos gráficos. No exemplo das capas que apresentam fotos de bandas como principal elemento pictórico, verificou-se a relação dessas com capas criadas para bandas de rock pertencentes ao póspunk e à new wave estadunidense e britânica, bem como uma recorrência na postura e no enquadramento dos integrantes das bandas retratadas nas fotos (Moretto \& Farias, 2020).

\section{Elaboração de um modelo de análise visual}

Após análises preliminares, percebeu-se que as capas poderiam ser analisadas em quatro níveis. No primeiro nível estariam os elementos pictóricos, os verbais e os esquemáticos, observados separadamente. No segundo, a composição visual das capas, isto é, a combinação ou o arranjo visual dos elementos identificados no nível anterior. No terceiro nível, as capas seriam observadas enquanto embalagens integrais (objetos tridimensionais), isto é, considerando-se a primeira capa (face principal e foco desta pesquisa), a contracapa e, até 
mesmo, o encarte e o selo aplicado ao disco de vinil. Já no quarto nível, as capas seriam estudadas enquanto partes de um conjunto, buscando-se identificar aspectos recorrentes e conformadores de uma linguagem visual característica do todo dessa coleção de artefatos gráficos. A tabela 2 sintetiza as 12 possibilidades (ou instâncias, numeradas de 1.1 a 4.3) de análise dessas peças gráficas.

Tabela 2: Instâncias de análise visual de conjuntos de artefatos gráficos.

\begin{tabular}{|c|c|c|c|c|}
\hline & $\begin{array}{l}1^{\circ} \text { nível } \\
\text { elementos visuais } \\
\text { constitutivos }\end{array}$ & $\begin{array}{l}2^{\circ} \text { nível } \\
\text { composição } \\
\text { visual }\end{array}$ & $\begin{array}{l}3^{\circ} \text { nível } \\
\text { peça gráfica } \\
\text { (objeto } \\
\text { tridimensional) }\end{array}$ & $\begin{array}{l}4^{\circ} \text { nível } \\
\text { conjunto de } \\
\text { peças gráficas }\end{array}$ \\
\hline $\begin{array}{l}\text { dimensão } \\
\text { sintática }\end{array}$ & $\begin{array}{l}1.1 \\
\text { elementos } \\
\text { pictóricos, } \\
\text { verbais e } \\
\text { esquemáticos, } \\
\text { observados de } \\
\text { modo isolado } \\
\text { quanto a suas } \\
\text { formas, tamanhos e } \\
\text { tratamento gráfico } \\
\text { (morfologia) }\end{array}$ & $\begin{array}{l}2.1 \\
\text { articulação de } \\
\text { elementos: } \\
\text { equilíbrio, peso, } \\
\text { alinhamento, } \\
\text { hierarquia, } \\
\text { homogeneidade ou } \\
\text { heterogeneidade } \\
\text { de tratamento } \\
\text { (sintaxe) }\end{array}$ & $\begin{array}{l}3.1 \\
\text { articulação visual } \\
\text { das soluções } \\
\text { formais entre as } \\
\text { diversas } \\
\text { partes do artefato } \\
\text { gráfico (como capa, } \\
\text { contra capa, } \\
\text { encarte, selo), } \\
\text { lógica produtiva } \\
\text { (impressão e } \\
\text { distribuição) }\end{array}$ & $\begin{array}{l}4.1 \\
\text { recorrência } \\
\text { de formas, } \\
\text { composições } \\
\text { e demais } \\
\text { características } \\
\text { observadas } \\
\text { nos níveis } \\
\text { anteriores } \\
\text { (características } \\
\text { plurais ou } \\
\text { singulares) }\end{array}$ \\
\hline $\begin{array}{l}\text { dimensão } \\
\text { semântica }\end{array}$ & $\begin{array}{l}1.2 \\
\text { expressividade, } \\
\text { impressões } \\
\text { causadas, } \\
\text { significados } \\
\text { e relações } \\
\text { estabelecidas } \\
\text { pelos elementos } \\
\text { visuais }\end{array}$ & $\begin{array}{l}2.2 \\
\text { expressividade, } \\
\text { impressões } \\
\text { causadas, } \\
\text { significados } \\
\text { e relações } \\
\text { estabelecidas } \\
\text { pela articulação de } \\
\text { elementos }\end{array}$ & $\begin{array}{l}3.2 \\
\text { expressividade, } \\
\text { impressões } \\
\text { causadas, } \\
\text { significados } \\
\text { e relações } \\
\text { estabelecidas pela } \\
\text { peça gráfica e } \\
\text { valores atribuídos } \\
\text { aos materiais }\end{array}$ & $\begin{array}{l}4.2 \\
\text { expressividade, } \\
\text { impressões } \\
\text { causadas e } \\
\text { relações } \\
\text { estabelecidas pelo } \\
\text { conjunto de peças } \\
\text { estudadas e com o } \\
\text { contexto }\end{array}$ \\
\hline $\begin{array}{l}\text { dimensão } \\
\text { pragmática }\end{array}$ & $\begin{array}{l}1.3 \\
\text { leiturabilidade, } \\
\text { efetividade da } \\
\text { comunicação de } \\
\text { cada elemento }\end{array}$ & $\begin{array}{l}2.3 \\
\text { leiturabilidade, } \\
\text { efetividade da } \\
\text { comunicação da } \\
\text { composição }\end{array}$ & $\begin{array}{l}3.3 \\
\text { leiturabilidade, } \\
\text { efetividade da } \\
\text { comunicação da } \\
\text { peça gráfica }\end{array}$ & $\begin{array}{l}4.3 \\
\text { efetividade de } \\
\text { entendimento do } \\
\text { conjunto de peças } \\
\text { gráficas }\end{array}$ \\
\hline
\end{tabular}

Assim como afirma Farias (2016) em seus apontamentos para um modelo de análise semiótica para a tipografia, seria importante observar que nem sempre é possível, ou necessário, realizar análises que levem em consideração a totalidade das dimensões (sintática, semântica e pragmática) em todos níveis de análise descritos. Devem ser determinadas, então, quais das doze instâncias, decorrentes do cruzamento das três dimensões com os quatro níveis de leitura propostos, são pertinentes aos objetivos estabelecidos para o entendimento da linguagem visual do corpus.

O modelo permite que se identifiquem e descrevam elementos e aspectos visuais (dimensão morfológica e sintática) para que seus potenciais comunicacionais (dimensão semântica) e seus impactos na cultura e sociedade (dimensão pragmática) sejam analisados 
com base na visão de historiadores, teóricos do design gráfico e do próprio pesquisador. A intenção é que as análises parciais desses grupos e subgrupos de artefatos gráficos que apresentam características comuns colaborem para o entendimento da linguagem visual do conjunto total. Pretende-se, assim, uma compreensão mais aprofundada das peças gráficas, seus conteúdos, suas técnicas, incluindo a relação entre sua linguagem visual e a cultura visual do período.

\section{Detalhamento e possibilidades de aplicação do modelo de análise}

Para aprofundar a compreensão do modelo, apresenta-se o detalhamento de algumas das instâncias descritas (tabela 2), bem como exemplos de possíveis aplicações das análises propostas. Buscando um encadeamento mais lógico do raciocínio, serão focadas as instâncias 1.1, 2.1, 3.1 e 4.1 (que compõem a dimensão sintática da análise), bem como as instâncias 4.2 e 4.3, que conformam, respectivamente, as análises semântica e pragmática da linguagem visual de conjuntos de artefatos gráficos.

A instância 1.1 do modelo envolve a análise morfológica da peça gráfica, observando seus elementos visuais constitutivos que, segundo o teórico britânico Michael Twyman (1986), dividem-se em pictóricos, verbais e esquemáticos. Nesta análise, pode-se notar, por exemplo, a presença, ou não, de elementos verbais nas peças gráficas e suas características intrínsecas, como o desenho das letras, o uso de caixa alta e baixa, seus pesos e espacejamentos ou a aplicação de texturas e efeitos como distorção e deterioração. Nesta instância, os elementos visuais constitutivos são observados isoladamente.

$\mathrm{Na}$ instância 2.1, que é diretamente correlata à instância 1.1, aprofunda-se a análise sintática e examina-se a relação dos elementos constitutivos dentro da composição visual da peça gráfica. $O$ foco recai, então, sobre o enquadramento, o equilíbrio ou a hierarquia que se estabelece entre os elementos pictóricos, verbais e esquemáticos como, por exemplo, a relação entre dois elementos verbais com diferentes funções dentro de uma composição visual (o título de um livro e o nome do autor, ou o nome de uma banda e o título do álbum na capa de um disco).

$\mathrm{Na}$ instância 3.1 do modelo, propõe-se que sejam observadas as partes constituintes dos artefatos gráficos, como, por exemplo, capa, miolo, lombada e quarta capa de um livro ou capa (primeira face), contracapa, encarte e rótulo de um disco de vinil. Mais do que suas características individuais, procura-se averiguar as relações que estas partes estabelecem entre si, constatando se existe coerência formal ou da linguagem gráfica adotada em cada uma delas com o todo. No caso de artefatos gráficos essencialmente bidimensionais, como um cartaz ou um cartão de visita, o foco, nesta instância, pode ser a coerência produtiva da peça, observando-se técnica de impressão, suporte adotado etc, características que também podem ser examinadas nas partes de um livro, de uma capa de disco e em outras peças tridimensionais.

$\mathrm{Na}$ instância 4.1, considera-se o conjunto de artefatos gráficos pertencentes ao corpus da pesquisa, buscando-se identificar e analisar características recorrentes comuns a subconjuntos 
das peças gráficas em estudo, ou singularidades que permitam identificar inovações. A identificação dessas características plurais e singulares ajuda a compreender a linguagem visual de um determinado conjunto de artefatos gráficos produzidos por um designer ou por uma comunidade em um determinado período de tempo (Aragão, 2011). Isso pode se manifestar, por exemplo, na repetição de uma paleta de cores em um conjunto de rótulos de um tipo de bebida, ou no enquadramento adotado ao fotografar diferentes bandas de rock para capas de discos.

Esta última instância de análise (4.1) decorre das três instâncias anteriores, mas tende, também, a retroalimentar as primeiras à medida que características plurais podem, graças à sua recorrência, despertar a atenção do pesquisador para aspectos subvalorizados que merecem ser reavaliados. A busca por características plurais no conjunto de artefatos gráficos estudados acaba por determinar os aspectos pelos quais esses artefatos serão analisados e as subcategorias pelas quais eles serão reorganizados.

Em pesquisas que demandam a análise de um grande volume de artefatos gráficos, o foco dos estudos tende a recair sobre as instâncias do quarto nível (4.1, 4.2 e 4.3), podendo-se utilizar as análises pontuais de peças gráficas individuais, propostas nas instâncias dos demais níveis, para embasar o exame e o entendimento das características da linguagem visual do conjunto analisado. Uma vez identificadas as características visuais plurais e singulares no corpus (instância 4.1), propõe-se que, na instância 4.2, essas sejam analisadas em suas dimensões semânticas, buscando-se entender seus potenciais comunicacionais e suas relações com referências extra corpus. Já na instância 4.3, serão observadas suas dimensões pragmáticas, verificando, se possível, os impactos sociais, culturais, estéticos etc na sociedade que as produziu, e na qual circulam ou circularam.

A análise semântica das capas de disco do rock brasileiro dos anos 1980, por exemplo, buscou entender a relação dessas capas com as capas criadas para bandas de rock pertencentes ao pós-punk e à new wave estadunidense e britânica, que influenciaram musicalmente as bandas brasileiras. Outros aspectos comunicacionais em comum com as capas estrangeiras mencionadas, e identificados nesta instância, foram o enquadramento e a postura dos integrantes das bandas retratados com certo ar de desdém desafiador, um pouco rebelde, e sempre encarando a câmera. A ressonância dessas características entre o público jovem nos anos 1980, manifestada no sucesso das bandas e nas vendas desses discos, bem como o fato de terem se tornado ícones de uma geração, podem direcionar a análise e o entendimento de seus aspectos pragmáticos.

\section{Exemplo de aplicação do modelo}

A capa do disco de vinil Revoluções por minuto da banda RPM de 1985 (Figura 3) pode exemplificar a aplicação do modelo proposto. Considerando-se a instância 1.1 do modelo, observam-se três elementos constitutivos na peça gráfica estudada: um pictórico e dois verbais. O elemento pictórico ocupa todo o campo gráfico: trata-se de uma fotografia em alto contraste, reproduzida em preto e vermelho sobre fundo amarelo, na qual foram retratados três 
dos quatro integrantes da banda. Complementado a imagem, nota-se intervenções lineares com cerca de $5 \mathrm{~cm}$ de comprimento nas cores verde e azul que, no conjunto, acabam por formar um padrão que ocupa quase toda a área da capa, deixando resguardados os rostos dos músicos. O nome da banda encontra-se junto à borda superior da capa, grafado em caixa alta e na cor azul, com letras geométricas desenhadas sem contraformas, medindo cerca de $5 \mathrm{~cm}$ de altura. $\mathrm{O}$ título do álbum, encontra-se junto à borda inferior da capa, grafado em caixa baixa, em preto, com uma fonte tipográfica sem serifa, com cerca de $2 \mathrm{~cm}$ de altura.

Figura 3: Capa, contracapa e página do encarte do disco Revoluções por minuto/RPM (criação de Alex Flemming, fotos de Rui Mendes, direção de arte de Geraldo Alves Pinto e Ricardo Leite, 1985/Brasil).
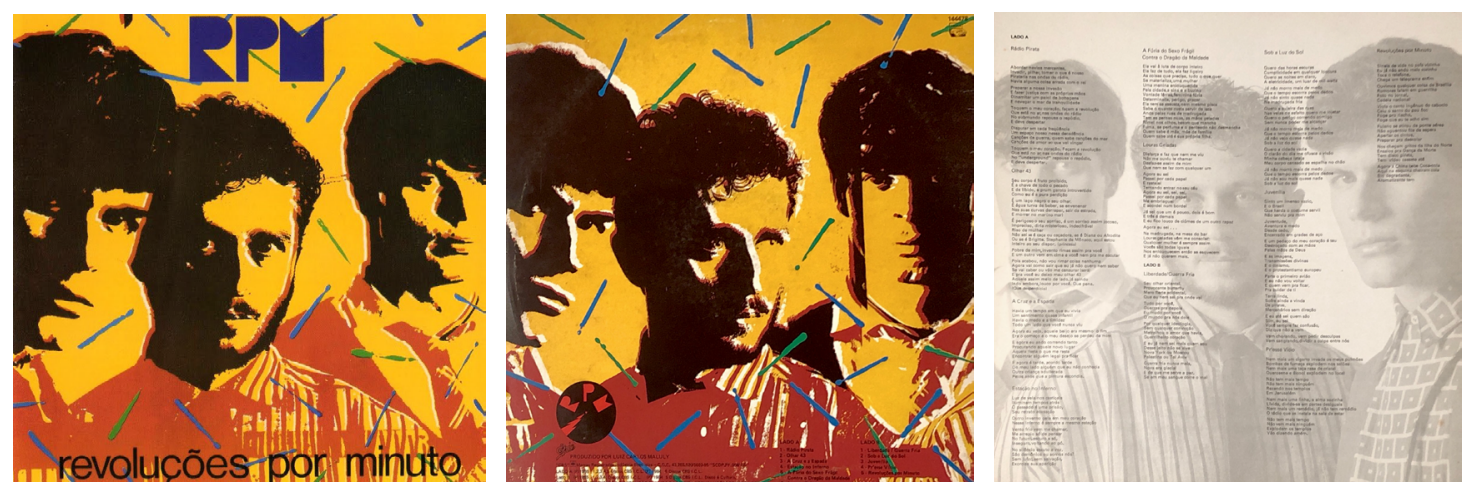

Quando consideradas as relações que se estabelecem entre os elementos constitutivos da composição visual da capa (instância 2.1), percebe-se que o nome da banda, dado o seu posicionamento, tamanho, cor e o contraste com o fundo, é o elemento verbal principal, enquanto que o título do álbum, com menor destaque, é o elemento verbal secundário. Os dois elementos verbais encontram-se sobre o elemento pictórico, que lhes serve de fundo.

Já na instância 3.1, observa-se a relação da capa com a contracapa, o encarte e o rótulo circular que foi aplicado sobre o disco de vinil. Percebe-se, assim, que uma outra fotografia da banda com o mesmo tratamento gráfico foi utilizada como elemento pictórico na contracapa, servindo de fundo para a disposição de um selo com o nome da banda, o logo da gravadora e dois grupos de elementos verbais, contendo dados técnicos e a lista de músicas, compostos com fonte tipográfica sem serifa, em corpos pequenos, na cor preta, na parte inferior da composição. Há forte coerência visual entre a linguagem gráfica da capa e da contracapa.

O encarte, por sua vez, é formado por uma única lâmina, sem dobras, que apresenta fotografias da banda em preto e branco nos dois lados. Sobre as fotos estão dispostas, de um lado, as letras das músicas, e, do outro, informações sobre os integrantes da banda, instrumentos utilizados e ficha técnica da produção do disco. Apesar das fotos usadas no encarte e na capa/contracapa aparentarem terem sido feitas durante uma mesma sessão fotográfica, a ausência de tratamento gráfico no encarte prejudica a identidade entre as partes. O rótulo aplicado ao disco de vinil, parece ser um rótulo padrão, dispondo o logo da gravadora e a lista de músicas de cada um dos lados, e não tem relação visual com as demais partes do conjunto. 
Quanto aos aspectos produtivos ${ }^{2}$, que também podem ser observados na instância 3.1, nota-se que toda a embalagem foi impressa em offset, tendo por suporte um papel cartão, na capa/contracapa, e um papel não revestido de baixa gramatura, no encarte interno.

$\mathrm{Na}$ observação de um conjunto maior de capas, observa-se que estas soluções produtivas eram o padrão da indústria fonográfica no período estudado.

O nível 4 de análises (instâncias 4.1, 4.2 e 4.3) pressupõe um conjunto de artefatos gráficos a serem analisados a fim de constatar se aspectos observados em instâncias iniciais, na análise individual de peças gráficas, encontram ressonância em um determinado corpus. A análise baseada na instância 4.1, aplicada às capas de disco em estudo, revelou algumas características plurais, também presentes na capa aqui analisada. Entre essas características, destacam-se o uso de foto da banda como elemento pictórico ocupando grande parte da área da capa, intervenções gráficas na foto da banda, nome da banda como principal elemento pictórico localizado no topo da composição, e o título do álbum como elemento verbal secundário, disposto na parte inferior da capa.

Figura 4: Capa dos discos Outlandos d'Amour/The Police (Michael Ross, 1978/Inglaterra) e Soda Stereo/Soda Stereo (designer desconhecido, 1984/Argentina). .
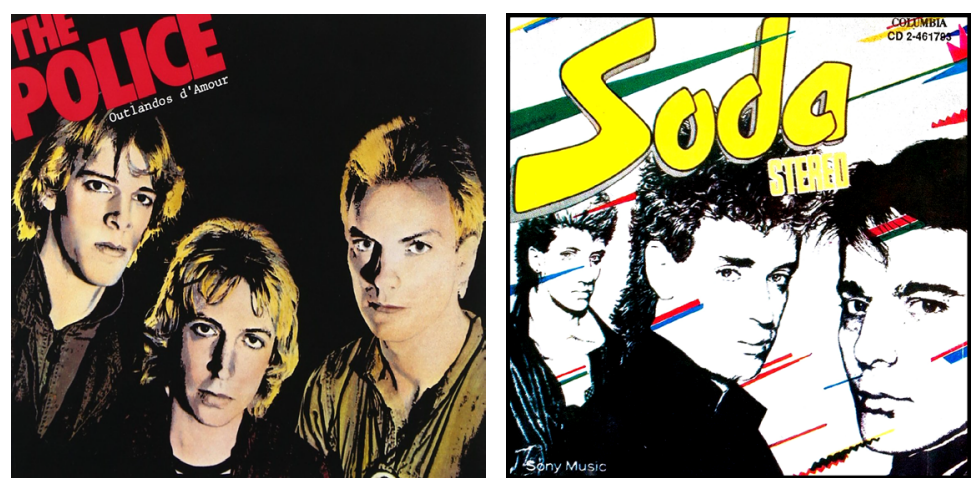

Em relação aos aspectos semânticos do conjunto de peças gráficas (instância 4.2) do qual a capa de Revoluções por minuto (figura 3) faz parte, buscou-se verificar se os elementos visuais plurais identificados no conjunto remetem a referências socioculturais do contexto no qual foram criados ou, até mesmo, a outras peças gráficas criadas em outros contextos sociais, ligados ao universo do rock dos anos 1980 de outros países. No caso específico da capa aqui analisada, foram encontradas duas capas de disco do mesmo período (figura 4) com linguagem visual semelhante (fotografias com enquadramentos e intervenções gráficas similares), evidenciando recorrência estética e de espírito da época (Figura 4), que possivelmente buscava traduzir visualmente aspectos como modernidade e juventude.

\footnotetext{
${ }^{2}$ O disco de vinil, ou Long Play (LP), é um suporte desenvolvido no final da década de 1940 para a reprodução musical, que usa um material plástico (vinil) que registra informações de áudio codificadas em pequenas ranhuras. O vinil é delicado e qualquer arranhão pode comprometer a qualidade de reprodução. Os discos são, tradicionalmente, protegidos por uma embalagem com diversas funções, como: acondicionamento, transporte, proteção, manuseio e comunicação visual. Estas embalagens são, geralmente, confeccionadas em papel cartão, em formato de envelope quadrado $(31$ x $31 \mathrm{~cm})$, com um dos lados abertos para a inserção do disco.
} 
A identificação de recorrências como esta traz indícios de que os artefatos gráficos do corpus estudado mantêm relações com outros artefatos gráficos produzidos pela indústria fonográfica em contextos semelhantes (mesma época, mesmo gênero musical), evidenciando, também, as intenções projetuais de seus designers.

Os impactos dessas formas plurais, observadas em diversos artefatos do corpus (e extra corpus), e como as pessoas os percebem é o foco da análise pragmática proposta na instância 4.3. Esta é uma análise que implica certo grau de subjetividade, variando de acordo com os grupos sociais por onde estes artefatos circularam e circulam, com suas referências culturais e com o tempo.

\section{Considerações finais}

O modelo proposto busca estabelecer critérios e procedimentos para identificação e análise de linguagens visuais comuns a conjuntos de artefatos gráficos produzidos em determinado lugar em um determinado período, partindo de elementos e aspectos pontuais. Para tanto, o foco deste modelo recai sobre as características (visuais, materiais etc) recorrentes observadas em um determinado corpus.

Muitas das etapas propostas neste modelo já foram colocadas em prática na análise das capas de disco do rock brasileiro dos anos 1980, e atenderam a seus propósitos. Outras, como a análise do conjunto das capas nas dimensões semântica e pragmática (instâncias 4.2 e 4.3), precisam ser investigadas mais a fundo para avaliar em que medida colaboram para 0 entendimento da linguagem visual de um conjunto de artefatos gráficos.

No que se refere à análise das capas de disco do rock brasileiro dos anos 1980, seu aprimoramento poderia envolver, no futuro, a análise de outros conjuntos de capas de discos, de outras épocas e outros estilos musicais, ou de outros tipos de artefatos gráficos, como cartazes e capas de livros, para verificar sua especificidade e sua eficácia nesses outros contextos.

\section{Agradecimento}

A pesquisa aqui relatada teve apoio da CAPES, CNPq, e Unión Iberoamericana de Universidades.

\section{Referências bibliográficas}

Aragão, Isabella. (2011). "O plural e o singular nas composições visuais dos rótulos de bebida". In: Campello, Silvio \& Aragão, Isabella (eds.). Imagens comerciais de Pernambuco: ensaios sobre os efêmeros da Guaianases, pp. 93-113.

Farias, Priscila L. (2016). Semiótica e tipografia: apontamentos para um modelo de análise. Cadernos de Estudos Avançados em Design: Design e Semiótica: 45-56. Barbacena: EdUEMG. 
Goldsmith, Evelyn. (1980). Comprehensibility of illustration - an analytical model. Information Design Journal, vol. 1, pp. 204-213.

Lupton, E.; Phillips, J. C. (2008). Novos fundamentos do design. São Paulo: Cosac Naify.

Migliari, M. M. (2010). Tipografia pós-moderna nas Bienais da Associação dos Designers Gráficos: 1992-2009 [Postmodern typography at the Biennials of the Graphic Designers Association: 1992-2009]. PhD dissertation, Puc-Rio.

Moretto, P. \& Farias, P. L. (2020). 1980's Brazilian Rock Album Covers: A Visual Analysis. In: F. Vukic \& I. Kostešić, eds. Lessons to Learn? Past Design Experiences and Contemporary Design Practices. Proceedings of the 12th ICDHS.

Moretto, P. \& Farias, P. L. (2021). "Pesquisando capas de disco do rock brasileiro dos anos 1980: estratégias metodológicas para a coleta e a análise de dados". In: Anais do $4^{\circ}$ Seminário de Pesquisa do Programa de Pós-Graduação em Design da FAUUSP. São Paulo: Blucher [no prelo].

Twyman, Michael. (1986). "Articulating graphic language: a historical perspective". In: Wrolstad, Merald E.; Fischer, Dennis F. (orgs.). Toward a new understanding of literacy. Nova lorque: Praeger, p. 188-251.

\section{Sobre os autores}

Paulo Eduardo Moretto, Doutorando, FAUUSP, Brasil <pmoretto@gmail.com>

Priscila Lena Farias, Professora Associada, FAUUSP, Brasil <prifarias@usp.br 